\title{
EDITORIAL
}

\section{The Death of the Mother and Her Child Keeps on Bothering Developing Nations}

\section{Mirkuzie Woldie (MD, MPH), Health Systems Management Specialist, Jimma University, Ethiopia}

The global population reached 7 billion in 2011 and was observed to increase by more than half a million in the year 2012. Developing countries took $97 \%$ of this rapid increase in the world's population. It is also expected that the future growth in the global population will entirely occur in the poorest countries. This is a result of total fertility rates as high as 7.1 in countries like Nigeria and 6 in many other nations $(1,2)$.

Given this high rate of birth in low resource settings, it will not be fair if health policy makers, health managers and researchers are not worried. This is because in the absence of the necessary facilities and assistance it is highly likely that the physiological events during pregnancy and child birth may end up with morbidity and/or mortality of the mother and/or her child. The evidence shows that maternal mortality ratios (MMR) are still unacceptably high in many of the developing countries. To mention some examples from the African region: Chad (1100/100,000), Central Africa Republic $(890 / 100,000)$ and Sierra Leon $(890 / 100,000)$ (3). A recent estimate of maternal mortality ratio for Sub-Saharan Africa was 510 (95\%CI: 380-730) (4). Similar conclusions could also be made for perinatal mortality which includes still birth and early neonatal mortality. The recent estimate of perinatal mortality rate (PMR) for Africa in general was 62/1000 live births while West, Middle and East Africa had 76, 75, 58 per 1000 live births as an estimate, respectively (5).

The fifth Millennium Development Goal (MDG) aspired to reduce the MMR by $75 \%$ during the period 1990 to 2015 which corresponds to an average yearly decline of $5.5 \%$. Most African countries are not 'on track' to achieve this (6). On the other hand, the fourth
MDG called for a two third reduction of the mortality rate among children below the age of 5 year. The United Nation (UN) reported that the intended decline in child death will not be realized in much of the Sub-Saharan Africa and the Southern Asia. The organization stated: "Despite determined global progress in reducing child deaths, an increasing proportion of child deaths are in sub-Saharan Africa and Southern Asia. Four out of every five deaths of children under age five occur in these regions (7)."

Researching the role of underlying causes and why existing interventions are not leading to intended reductions in MMR and PMR are granted at any rate. However, there is a lack of reviews (both conventional literature reviews and systematic reviews) summarizing the trends and predictors of these critical development indicators in the African Region in general and Ethiopia in particular. Moreover, existing interventions and corresponding effects are not well documented to inform policy makers, researchers and health managers alike.

In this special issue of the Ethiopian Journal of Health Sciences, the authors present reviews on the trends and causes of MMR and PMR in the African region with significant emphasis to the situation in Ethiopia. There are also articles reviewing the existing interventions to address the problem of maternal and perinatal mortality in the Ethiopian setting. The authors have also developed a logic model (based on existing and newly recommended interventions) which they argued to be effective in possibly reaching the targets of 250/100,000 for MMR and 20/1000 live births for PMR by the year 2025 in Ethiopia.

DOI: http://dx.doi.org/10.4314/ejhs.v24i1.1S 
Hence, it is my pleasure to invite all readers to read through all of these 12 interesting articles (seven systematic reviews and five conventional literature reviews) hoping that you will find them to be significant additions to the existing pile of evidences we already have in the field of maternal and child health. I also urge you not to hesitate if you feel like sending any comments to the authors and the journal Editor.

\section{REFERENCES}

1. Population Reference Bureau. 2012 World Population Data Sheet. Accessed on 31 Aug. 14: http://www.jsk.gov.in/2012pop.pdf

2. Global Population Composition. Accessed on 31 Aug. 14:

https://www.census.gov/population/internat ional/files/wp02/wp-02004.pdf

3. World health organization. World Health Statistics 2013. Accessed on August 31, 2013:

http://www.who.int/gho/publications/world health_statistics/EN_WHS2013/pdf
4. WHO, UNICEF, UNFPA, The World Bank and the United Nations Population Division. Trends in maternal mortality: 1990-2013. Accessed on August 31, 2014: http://www.who.int/reproductivehealth/pub lications/monitoring/maternal-mortality2013/en/

5. World Health Organization. Neonatal and perinatal mortality: country, regional and global estimates. 2006. Accessed on September 1, 2014: http://whqlibdoc.who.int/publications/2006 19241563206_eng.pdf

6. WHO, UNICEF, UNFPA, The World Bank and the United Nations Population Division. Trends in maternal mortality: 1990-2013. Accessed on August 31, 2014: http://www.who.int/reproductivehealth/pub lications/monitoring/maternal-mortality2013/en/

7. United Nations. Millennium Development Goals and Beyond 2015. Accessed on September 1, 2014: http://www.un.org/millenniumgoals/childh ealth.shtml 